\title{
Induction of Skin Fibrosis in Mice Expressing a Mutated Fibrillin-1 Gene
}

\author{
Shinichiro Saito, ${ }^{1}$ Hiroyuki Nishimura, ${ }^{4}$ Robert G. Phelps, ${ }^{2}$ Imre Wolf, ${ }^{3}$ \\ Mihsa Suzuki, ${ }^{5}$ Tasuku Honjo ${ }^{4}$ and Constantin Bona ${ }^{1}$ \\ ${ }^{1}$ Department of Microbiology, \\ ${ }^{2}$ Department of Pathology, \\ ${ }^{3}$ Department of Biochemistry, Mount Sinai School of Medicine, New York, U.S.A. \\ ${ }^{4}$ Department of Medical Chemistry, Graduate School of Medicine, Kyoto University, \\ Kyoto, Japan \\ ${ }^{5}$ Center for Animal Resources Kumamoto University, Kumamoto, Japan \\ Accepted June 22, 2000.
}

\begin{abstract}
Background: Tight skin mice (TSK) bear a mutated Fibrillin-1 (Fbn-1) gene. Genetic studies show that the TSK mutation is closely associated with the Fbn-1 locus (0-0.7 cM). A previous study showed two recombinants between the Fbn-1 locus and the TSK mutation. TSK mutation and mutated Fbn-l gene cosegregate in Fl mice.

Materials and Methods: To elucidate the role of the mutated Fbn-l gene in occurrence of TSK syndrome, we generated transgenic ( $\mathrm{Tg}$ ) mice expressing mutated Fbn-1 gene. In another set of experiments, we injected normal mice after birth with a plasmid bearing mutated Fbn-l gene (pdFbn-1).
\end{abstract}

Results: Our results demonstrate that the pdFbn-1 Tg mice developed permanent cutaneous hyperplasia that was permanent. In mice injected as newborns with a plasmid bearing the sense pdFbn-1 gene, cutaneous hyperplasia was transient. In contrast to TSK mice, neither Tg nor mice injected with plasmid developed lung emphysema. The pdFbn-1 Tg and TSK mice spontaneously produced antitopoisomerase I and anti-Fbn-1 antibodies, as do humans afflicted by scleroderma; whereas, those injected with a plasmid containing the pdFbn-1 gene produced only anti-Fbn-1 autoantibodies.

Conclusions: The results suggest that, although cutaneous hyperplasia is due to mutated Fbn-1 gene, the TSK syndrome may be multifactorial.

\section{Introduction}

The tight skin (TSK) mouse, which develops a syndrome resembling human systemic sclerosis (1) and congenital fascial dystrophy (2), is the most thoroughly studied animal model for scleroderma. Although homozygous mice die in utero by 9 days of pregnancy, the heterozygotes survive and develop TSK syndrome (1). The TSK syndrome is characterized by cutaneous

Address correspondence and reprint requests to: Dr. C. Bona Department of Microbiology, Annenberg Bld. 16-60, Box 1124, Mount Sinai School of Medicine, One Gustave Levy Place, New York, NY 10029, U.S.A. Phone: 212-2416924; Fax: 212-423-0711; E-mail: bonac01@doc.mssm.edu hyperplasia (1), emphysema (3), cardiac hypertrophies (4), connective tissue hyperplasia in cartilage (1), and autoantibodies against human scleroderma target antigens (5). The central pathological feature of the TSK syndrome is fibrosis of skin and some internal organs subsequent to excessive synthesis and deposition of collagens $(6,7)$, glycosaminoglycans $(8)$, and other extracellular matrix proteins.

In contrast to human scleroderma, which is a multifactorial disease, the TSK syndrome is thought to be due to a single autosomal dominant gene mutation. This mutation was mapped to band F of chromosome 2 (1) close to the Fibrillin-1 (Fbn-1) locus (9). 
Siracusa et al. (10) described a tandem duplication of the Fbn-1 (pdFbn-1) gene in TSK/+ mice, comprising exons 17-40. In addition to a large duplication, the TSK gene exhibits numerous replacement mutations in $5^{\prime}$ and $3^{\prime}$ exons (11). The TSK syndrome cosegregates with pdFbn-1 gene in F1 mice (12). These observations suggest that pdFbn-1 gene may be the TSK mutation or, alternatively, that the Fbn-1 locus and TSK mutation are physically close and, therefore, cosegregate in Fl mice. Siracusa et al. (10) found no recombinants between the TSK mutation and the Fbn- 1 locus in 330 backcross progeny, consistent with the concept that pdFbn-l gene is the TSK mutation. However, Doute and Clark (13) found two recombinants in the backcross progeny obtained from crossing (TSK/+X Mus spretus) Fl X C57BL6/pa/pa. This observation suggests that the TSK mutation is not identical with pdFbn-1 gene.

Because of this discrepancy, we generated transgenic (Tg) mice expressing the pdFbn-1 gene or injected newborn C57BL/6 mice with a vector expressing the mutated gene to study the occurrence of the TSK syndrome. Our results showed that high copy number Tg mice developed cutaneous hyperplasia late in life. Newborn mice injected with a plasmid expressing the pdFbn-1 gene under the cytomegalo virus (CMV) promoter developed a localized and transient cutaneous hyperplasia, which was evident in the fourth and eighth week after the last injection of plasmid. None of these mice developed lung emphysema and cardiac hypertrophy characteristic of the TSK syndrome.

\section{Material and Methods}

Mice

C57Bl/6J, C57BL6 pa/pa, and TSK/+ mice were purchased from the Jackson Laboratory (Bar Harbor, ME).

\section{Generation of Transgenic Mice}

The (SNt) vector containing the pdFbn-1 gene (11) was digested with (Sal I) after which a $12.5 \mathrm{~kb}$ fragment of pdFbn-1 was separated on $0.7 \%$ agarose gel and extracted with a QIAEX II Gel Extraction Kit (Qiagen, Hilden, Germany). The fragment was cloned into a (BSSK) vector containing the chicken $\beta$-actin promoter and the direction of the pdFbn-1 gene was determined by restriction enzyme analysis. The linear DNA fragment containing TATA, chicken $\beta$-actin promoter, pdFbn-1 gene, and polyA was obtained with (Mul I) digestion (Fig. 1) and used to prepare Tg mice by injection into ova obtained from fertilized C57BL/6 mice. Four founders were obtained and were crossed with C57BL/6J mice to establish the pdFbn-1 transgenic lines.

\section{Construction of $p d F b n-1-p c D N A 3$}

The $12.5 \mathrm{~kb}$ fragment obtained as described above, was cloned into a Sal I-digested pcDNA3 vector (Invitrogen San Diego, Cal.) and the direction of pdFbn- 1 gene was determined by restriction enzymes analysis (Fig. 2).

\section{Primary Fibroblast Cell Lines}

Primary fibroblast cell lines were prepared from 8-day-old embryos obtained from TSK or pdFbn-1 Tg mice. The genotype of fibroblast cell lines was determined either by Southern blots analysis or by PCR.

\section{Immunization of Newborn Mice}

Newborn C57BL/6 mice were injected in the interscapular region 1, 3, and 6 days after the birth with $0.05 \mathrm{ml}$ saline containing $100 \mu \mathrm{g}$ plasmid bearing the sense or the anti-sense pdFbn-l gene.

\section{Southern Blots Analysis}

Genomic DNA was prepared either from mice tail biopsies or fibroblast lines, with a QIAGEN Tissue Kit (Qiagen). $10 \mu \mathrm{g}$ genomic DNA was digested with (Hind III) and separated on $0.8 \%$ agarose gel and blotted on Hybond ${ }^{\mathrm{TM}}-\mathrm{N}$ (Amersham, Buckinghamshire, England). The filter were hybridized overnight at $42^{\circ} \mathrm{C}$ with the ${ }^{32}$ P-labeled Fbn- 1 DNA probe with Ready-to-Go DNA beads (Pharmacia, Uppsala, Sweden) in the hybridization solution containing $50 \%$ formamide and finally washed in $0.1 \mathrm{X}$ standard saline citrate (SSC), $0.1 \%$ sodium dodecyle sulfate (SDS) at $65^{\circ} \mathrm{C}$. The Fbn-1 DNA probe corresponds to 4720-5446 bp of the cDNA. Using this probe, we previously were able to identify a distinct restriction fragment length polymorphism (RFLP) in TSK mice (12).

\section{Polymerase Chain Reaction (PCR) Analysis}

PCR analysis using genomic DNA was carried out for identification of the pdFbn-1 gene. Two primers were used: forward primer located in 


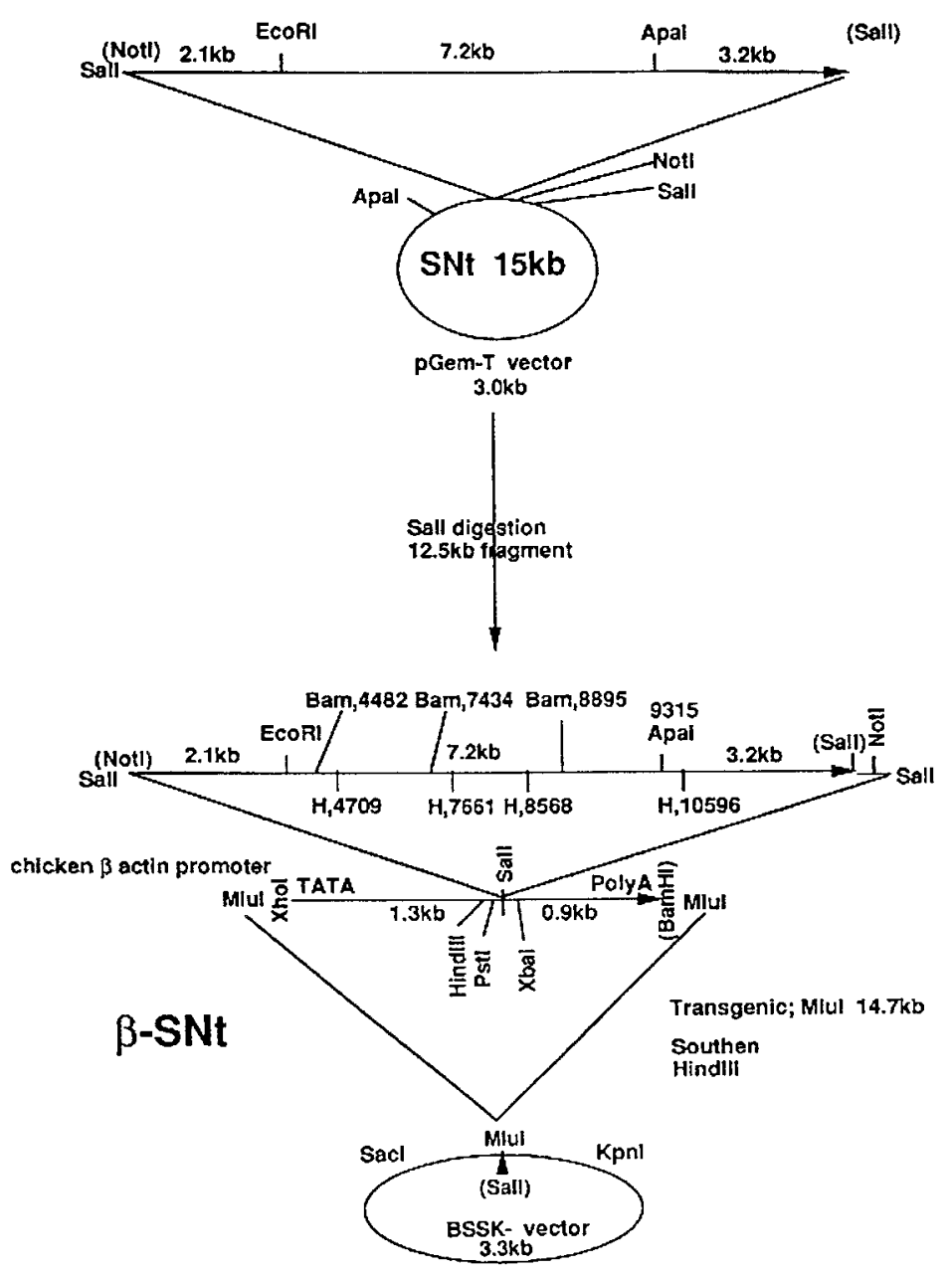

Fig. 1. Construction of plasmid expressing pdFbn-1 gene used to generated transgenic mice. pdFbn-1, plasmid bearing fibrillin-1 gene; EcoRI, ApaI, NotI, SNt, ( $\beta$-Snt, BSSK).

exon 40: 5' -TATAAATTCTTGCCCTGGA-3' and a reverse primer located at the break point of $3^{\prime}$ end of exon 40 and the $5^{\prime}$ end of the repeated exon 17: 5'-GCCTGATATTCCGCCATGCAATTATTTCCCCCG-3'. Cycling conditions were $95^{\circ} \mathrm{C}$ for $1 \mathrm{~min}$ primary denaturation, then $95^{\circ} \mathrm{C}$ for $30 \mathrm{sec}, 59^{\circ} \mathrm{C}$ for one min, and $72^{\circ} \mathrm{C}$ for $45 \mathrm{sec}$ for 30 cycle in a $50 \mu \mathrm{l}$ reaction volume.

\section{Reverse Transcription-polymerase Chain} Reaction (RT-PCR) Analysis

Total RNA was extracted from lung and kidney of $\mathrm{Tg}$ mice or from fibroblast lines. Singlestrand cDNA was synthesized with $10 \mu \mathrm{g}$ of total RNA using a SuperScript ${ }^{\mathrm{TM}}$ Preamplification System (GibcoBRL, Gaithersburg, MD.) PCR was carried out with the primers described above for pdFbn- 1 and with following primers for $\beta$-actin, which were used as an internal control: forward primer: 5'-TTTGAT-
GTCACGCACGATTTCC-3' and the reverse primer 5'-TTTGATGTCACGCACGATTTCC-3'. The same cycling conditions describe above were used.

\section{Light Microscopy}

Skin samples of $4.0 \mathrm{~cm}^{2}$ were removed from dorsal surface immediately below the neck in manner that minimized the stress. The samples were fixed for $16 \mathrm{hr}$ in buffered saline containing formalin, cut into 2 to $3 \mathrm{~mm}$-wide strips, dehydrated, and embedded in paraffin according to routine histological methods. The thickness of the skin was determined on sections stained with hematoxyline-eosine (HE) by measuring it from the top of granular layer to the junction between dermis and subcutaneous fat as previously described (14). The lungs were inflated, and then fixed and processed by the same methods, and the ex- 


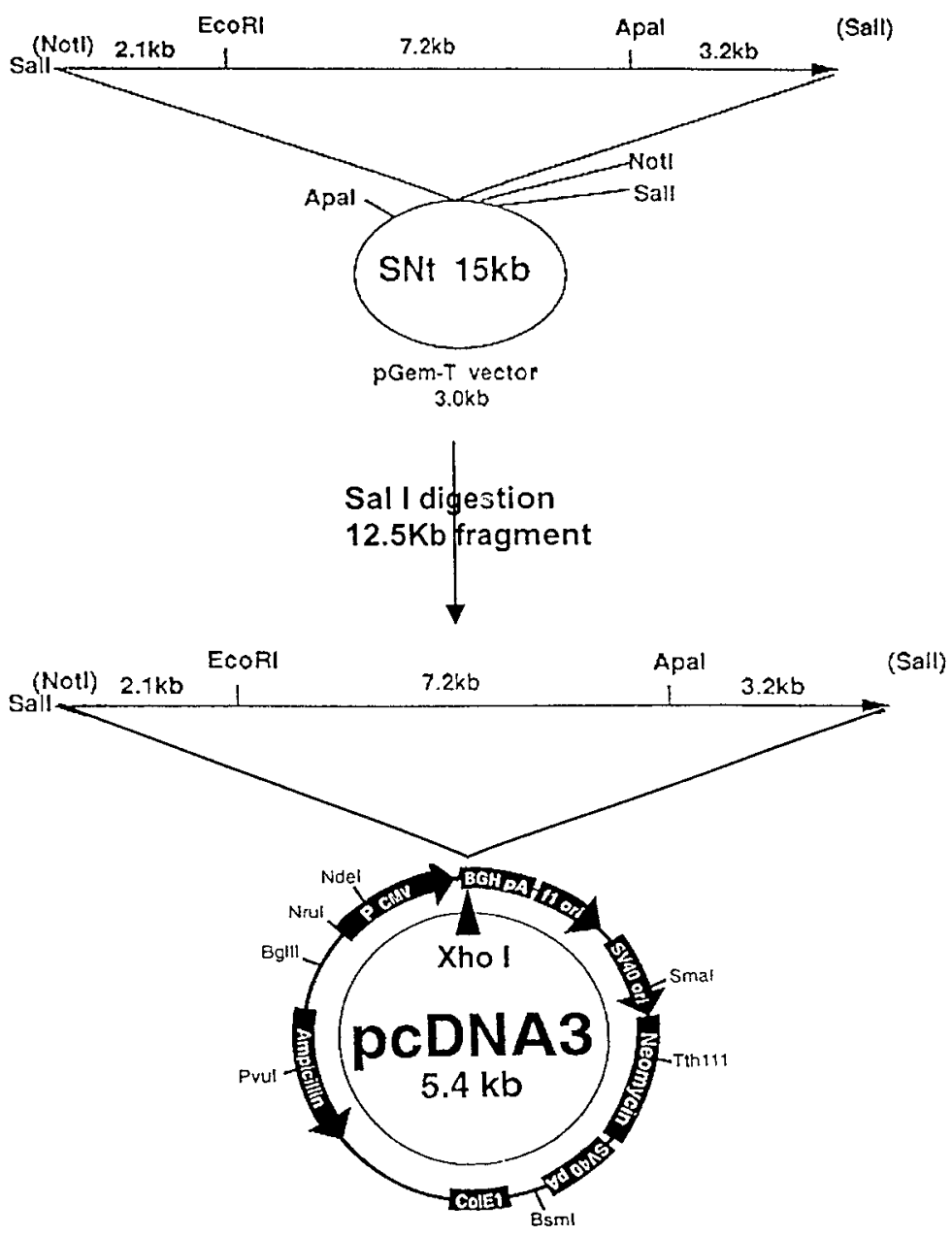

Fig. 2. Construction of pdFbn-1 pcDNA3 vector. pdFbn-1, plasmid bearing fibrillin-1 gene; EcoRI, NotI, ApaI, SalI, SNt, SV40, BGHpA, etc.

tent of air space dilatation and cellular infiltrate were analyzed.

\section{Determination of Hydroxyproline}

Content in Skin Tissue

Punch biopsies $(6 \mathrm{~mm}$ diameter) from wellshaved skin samples were treated overnight with chloroform:methanol [2:1 volume per volume $(\mathrm{v} / \mathrm{v})]$ to remove the fat, and dried by Speed Vac centrifugation, Baxter Scientific Products Roundlake, IL. Dried samples were weighed and acid hydrolyzed at $110^{\circ} \mathrm{C}$ for $24 \mathrm{hr}$. The hydrolysates were dried and analyzed for hydroxyproline content as previously described (7). Briefly, dried samples were dissolved in $200 \mu \mathrm{l}$ of water and filtered on millipore filters. Samples aliquots of $20 \mu \mathrm{l}$ were diluted 10-fold and used for the analysis of amino acid composition in a Hewlett-Packard Amino Acid Analyzer (Portou Instruments Tarzana, CA). The amount of hydroxyproline was expressed as $\mu \mathrm{g}$ per $\mu \mathrm{g}$ dry tissue. Previously, Hakateyama et al. (15) showed that there was a good correlation $(\mathrm{r}=$ 0.87) between the thickness of skin and hydroxyproline content in TSK/+ mice (15).

Quantitation of Serum Anti-topoisomerase and Anti-Fbn-1 Autoantibodies

The presence of antibodies was determined in radioimmunoassay (RIA) using microtiter plates coated with $3 \mu \mathrm{g}$ purified topoisomerase 1 protein (GibcoBRL, Gaithersburg, MD), $1 \mu \mathrm{g}$ fusion Fbn-1 protein corresponding to 367-425 amino acid residues, prepared according to a previously described technique (16), or with bovine serum albumin (BSA). After coating, the plates were extensively washed in phosphate-buffered saline (PBS), blocked with 1\% BSA in PBS, and then incubated for $30 \mathrm{~min}$ at room temperature with $1: 30$ dilution of serum, washed, and incubated 
for 90 min with $50,000 \mathrm{cpm}$ of ${ }^{125}$ I-labeled rat anti-mouse $\kappa$-antibody per well. Bound radioactivity was measured in a $\gamma$-counter. Since we do not have anti-topoisomerase or anti-Fbn-1 monoclonal antibodies for the construction of standard curves, enabling the calculation of the concentration of antibodies, we expressed the results as cpm after subtraction of binding to BSA from the binding to topoisomerase 1 or Fbn-1.

\section{Statistical Analysis}

Correlation coefficients were calculated using the 2-tail Fishers exact test (SAS Institute, Cary, NC). Differences between the groups were considered to be statistically significant when p-value was $<0.05$.

\section{Results}

\section{Determination of Genotype of pdFbn-1 Transgenic Mice}

Southern blots or PCR determined the genotype of progeny from crossing the four founders with C57BL/6 mice. Figure 3 shows an additional $4.7 \mathrm{~kb}$ band in Southern blots using genomic DNA digested with Hind III from two founders (TS4-1 and TS4-3), one Tg mouse, one fibroblast line obtained from low copy, and three lines from high copy number $\mathrm{Tg}$ mice. This band was missing in the DNA obtained from the C57Bl/6 fibroblast line. As we previously reported (17), with the reverse and forward primers corresponding to intron 17 and exon 40, a single $323 \mathrm{~kb}$ band was detected in PCR in the case of TSK/+ mice, but not in other murine strains (12). Therefore, in further experiments we used only the PCR to genotype the Tg mice, since the PCR results unanimed with Southern blots analysis. High number and low number copy $\mathrm{Tg}$ mice were determined by Southern blots, based on the intensity of $4.7 \mathrm{~kb}$ band.

The analysis of the expression of pdFbn- 1 gene was carried out by RT-PCR. Figure 4 shows that cDNA transcribed from RNA extracted from the lung of high or low copy number Tg and TSK/+ mice had a $377 \mathrm{bp}$ band (lane 2, 3, and 5, respectively); whereas, that extracted from C57BL/6 did not (lane 4). The same results were obtained with DNA transcribed from RNA extracted from TSK/+ and high or low copy number Tg fibroblast lines. It was noteworthy that the intensity of high copy

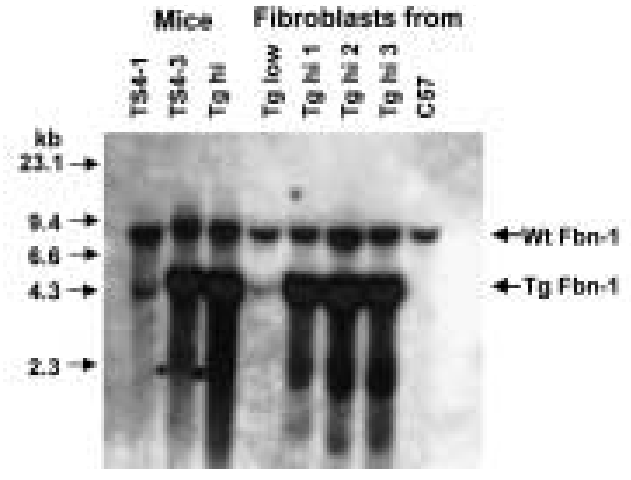

Fig. 3. Southern blots analysis of pdFbn-1 transgenic mice and of fibroblast lines. Genomic DNA was digested with (HindIII) and the filters were hybridized with ${ }^{32} \mathrm{P}$-labeled Fbn-1 probe as previously described (10). Fbn-1, fibrillin-1 gene; pdFbn-1, plasmid bearing Fbn-1; TS, Tg founder; Tg hi, Tg high copy number; Tg low, Tg-low copy number; wt, wild-type.

number Tg mice band was stronger than that of low copy number $\mathrm{Tg}$ mice in both Southern blots (Fig. 3, lane Tg low) and RT-PCR (Fig. 4, lane 3).

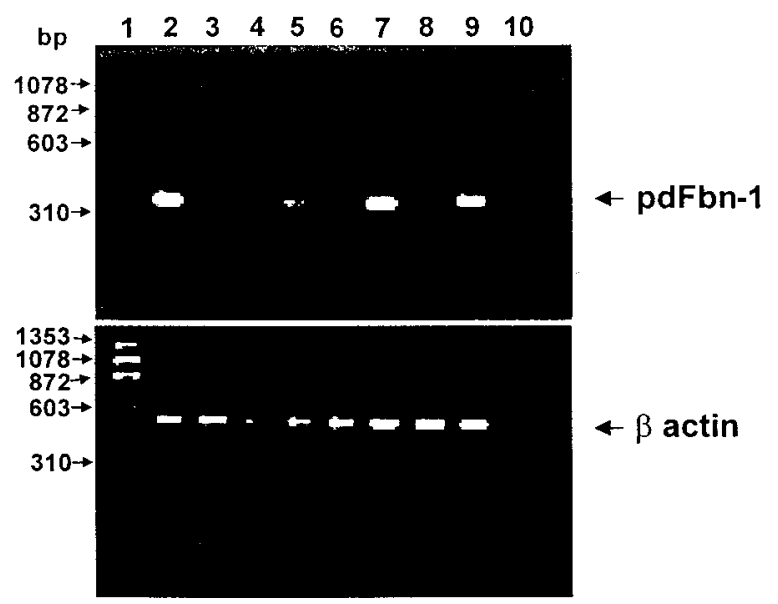

Fig. 4. Reverse transcription-polymerase chain reaction (RT-PCR) analysis of the expression of pdFbn-1 gene. $10 \mu \mathrm{g}$ RNA extracted from lung or kidney or fibroblast lines was used to synthesize single-strand DNA, according to the method described in "Material and Methods." lane 1: $\Phi$ x174/ HaeIII; lane 2: lung cDNA from high copy number transgenic ( $\mathrm{Tg}$ ) mouse; lane 3: lung cDNA from low copy number Tg mouse; lane 4: lung cDNA from C57Bl/6 mouse; lane 6: lung cDNA from tight skin (TSK)/+ mouse; lane 7: cDNA from low copy number Tg fibroblast line; lane 8: cDNA from low copy number Tg fibroblast line; lane 9: cDNA from C57BL/6 fibroblast line; line 9: cDNA from TSK/+ fibroblast line; lane 10: no cDNA. Low copy number $\mathrm{Tg}$ mice were obtained from breeding of C57Bl/6 mice with founder TS4-1 and high copy number Tg mice with founder TS4-3 or TS4-4 mice. pdFbn-1, plasmid bearing fibrillin-1 gene. 


\section{Histopathology of Skin and Lung}

In comparison to C57Bl/6 mice, the TSK mice exhibited a massive hyperplasia of connective tissue in both superficial and deep dermis. The hyperplasia extended around adnexa and panniculus carnosus, replaced the subcutaneous fat tissue, and was associated with a substantial reduction of hair follicles. An increase of collagen was evident (Fig. 5, upper left panel). Cutaneous hyperplasia was also observed in 3- and 6-month-old high copy number Tg mice, particularly in superficial dermis. In some 6-monthold mice, the hyperplasia extended to deep dermis and in others, into fat tissue (compare Fig. 5 center bottom and upper right panels).

In addition to cutaneous hyperplasia, the TSK mice develop lung emphysema and cardiac hypertrophy $(3,8)$. Therefore, we studied the histopathology of the lung in TSK and Tg mice. Figure 6 shows an enlargement of alveolar ducts and of alveoli with little cellular infiltration in lung sections obtained from TSK mice. The size of alveoli in high copy number Tg mice was comparable to control mice, but showed varying degrees of cellular infiltration in the interstitium. Lung histopathology of 6-month-old low copy number Tg mice was normal.

\section{Development of TSK Syndrome in pdFbn-1 Tg Mice}

For a long time, the TSK phenotype was identified clinically by inspection of skin stiffness (1). Hatakeyama et al. (15) showed striking correla- tion between skin thickness, dermal hydroxyproline, soluble collagen content, and anti-topoisomerase I autoantibodies. For example, the correlation index between the presence of anti-topoisomerase antibodies and skin thickness was $r=0.65336$, and with soluble collagen type $\mathrm{I}$ was $\mathrm{r}=0.55896$ (15). Murai et al. (16) found anti-Fbn-l autoantibodies in TSK mice, but not in other murine strains.

In the present study, these objective criteria were used to define the TSK syndrome. The data in Table 1 show a significant increase of dermal hydroxyproline content in 3-month-old high copy number Tg mice $(p=0.032)$ and of hydroxyproline and skin thickness in 6-monthold Tg mice ( $p=0.199$ for skin and $p=0.017$ for hydroxyproline, respectively). TSK mice spontaneously produced anti-topoisomerase and antiFbn- 1 autoantibodies ( $p=0.0022$ and $p=0.004$, respectively, compared with normal mice). A significant increase of anti-topoisomerase ( $p=$ $0.079)$ and less significant increase $(p=0.212)$ of anti-Fbn- 1 autoantibodies was observed only in 6-month-old high copy number Tg mice. No significant increase of anti-Fbn-1 autoantibodies was observed in all groups of $\mathrm{Tg}$ mice studied, except the TSK/+ mice $(p=0.0004)$.

These results showed that the high copy number Tg mice did develop cutaneous hyperplasia and, late in the life, autoantibodies pathognomonic for scleroderma, but did not develop lung emphysema. An increased content of dermal hydroxyproline preceded
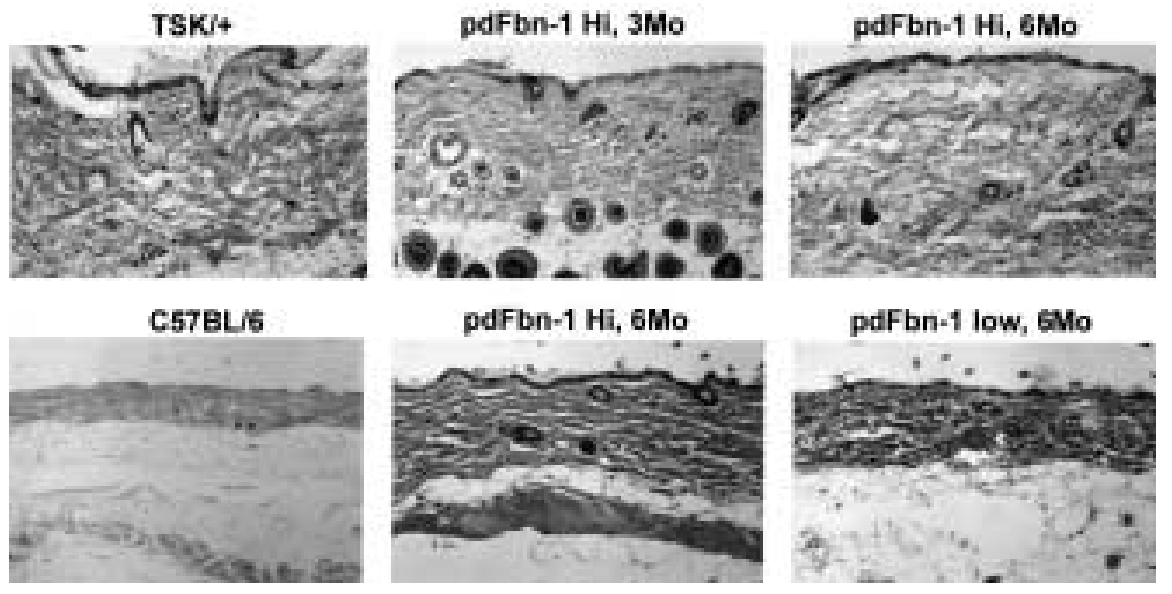

Fig. 5. Histopathology of the skin from pdFbn-1 mice. The plasmid bearing fibrillin-1 gene (pdFbn-1) hi and lo correspond to skin collected from high and low copy number 3- and 6-month-old transgenic ( $\mathrm{Tg})$ mice. Skin from two 6-month-old Tg mice are presented in this figure.
Low copy number Tg mice were obtained by breeding of founder \# 1 with C57Bl/6 mice; whereas, high copy number $\mathrm{Tg}$ mice were obtained by breeding of founder \#3 or 4 . All sections were stained with Hematoxyline-eosine (HE) (30X). 

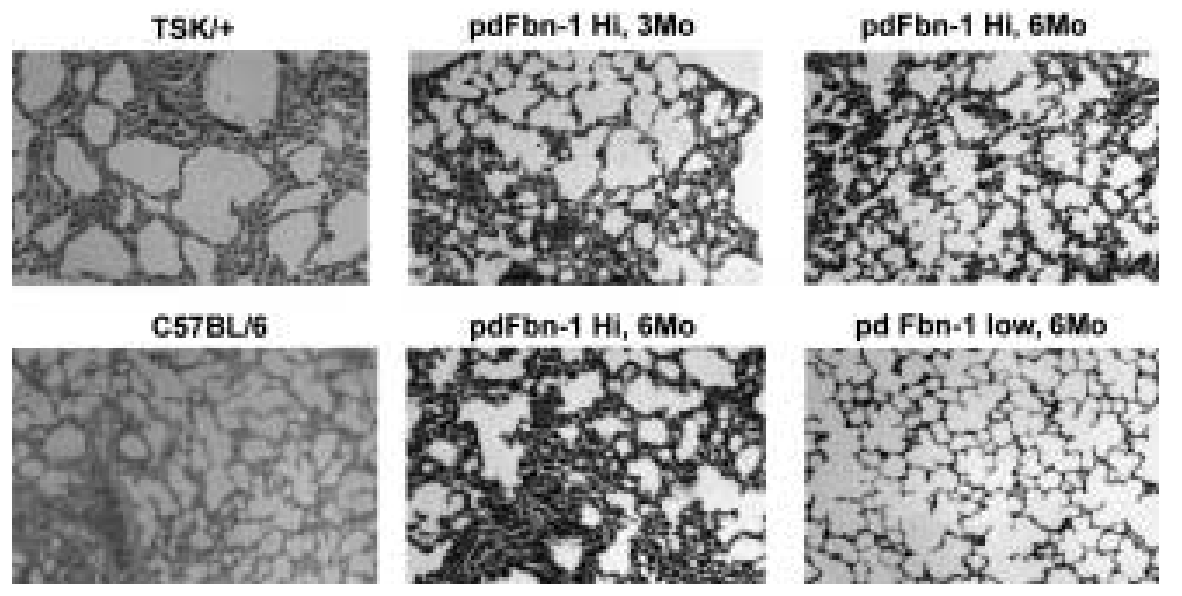

Fig. 6. Histopathology of the lung from plasmid bearing fibrillin-1 gene (pdFbn-1) mice. Lung sections were obtained from tight skin mice (TSK/)+, $\mathrm{C} 57 \mathrm{Bl} / 6$, and high and low copy transgenic (Tg)

skin thickening, since it was observed in 3month-old Tg mice, which did not exhibit an overt hyperplasia. In contrast to TSK mice that all exhibited cutaneous hyperplasia, only $12.5 \%$ of low copy and $73 \%$ of high copy number $\mathrm{Tg}$ developed it.

\section{Induction of Cutaneous Hyperplasia with a Plasmid Expressing the pdFbn-1 Gene}

It is well known that genes inserted in vectors, together with strong promoters, are expressed in various organs after injection of plasmids (18). Induction of strong immune responses were described after injection of plasmids containing genes from bacteria, viruses, and parasites (19). Thus, we constructed a vector containing pdFbn-1 gene expressed under the mice. Two different 6-month-old high copy number $\mathrm{Tg}$ mice are shown, since they represent examples of lungs with or without cellular infiltration. Sections were stained with Hematoxyline-eosine (30X).

CMV promoter to study whether this plasmid can induce TSK syndrome. One-day-old C57BL/6 mice were injected s.c. in the dorsal region three times day 1,3 , and 6 days after birth with $100 \mu \mathrm{g}$ plasmid containing the sense or the anti-sense pdFbn-1 gene. Mice were scarified 2, 4, 8, and 12 weeks after completion of administration of plasmid.

Figure 7 shows that the histology of skin collected 2 to 8 weeks after the last injection of plasmid containing the sense gene, but not the anti-sense gene, exhibited cutaneous hyperplasia comparable to that observed in TSK or high copy number pdFbn-1 Tg mice. Although cutaneous hyperplasia was prominent at the site of injection of plasmid, the abdominal skin exhibited normal structure and thickness. The skin of mice collected 2 weeks after the last in-

Table 1. Characterization of tight skin mice (TSK) phenotype of the pd-Fbn-1 transgenic mice

\begin{tabular}{|c|c|c|c|c|c|c|c|c|c|c|}
\hline \multirow{2}{*}{$\begin{array}{l}\text { Mouse } \\
\text { Strain } \\
\text { C57BI/6 }\end{array}$} & \multirow{2}{*}{$\begin{array}{l}\text { Age } \\
3 \mathrm{Mo}\end{array}$} & \multirow{2}{*}{$\frac{\mathbf{N}}{6}$} & \multicolumn{2}{|c|}{$\begin{array}{c}\text { Skin Thickness } \\
(\mu \mathrm{m})\end{array}$} & \multicolumn{2}{|c|}{$\begin{array}{l}\text { Hydroxyproline Content } \\
(\mu \mathrm{mol} / \mu \mathrm{g} \text { dry tissue })\end{array}$} & \multicolumn{2}{|c|}{$\begin{array}{l}\text { Anti-Topo Ab } \\
\text { (cpm) }\end{array}$} & \multicolumn{2}{|c|}{$\begin{array}{l}\text { Anti-Fbn-1 Ab } \\
\text { (cpm) }\end{array}$} \\
\hline & & & $132 \pm 42$ & $\mathrm{P}$ & $518 \pm 88$ & $\mathrm{P}$ & $370 \pm 441$ & $\mathrm{P}$ & $2529 \pm 2743$ & $\mathrm{P}$ \\
\hline TSK/+ & $3 \mathrm{Mo}$ & 10 & $231 \pm 89$ & 0.019 & $955 \pm 361$ & 0.013 & $2266 \pm 1187$ & 0.0022 & $11150 \pm 5707$ & 0.004 \\
\hline Low & $\begin{array}{l}3 \mathrm{Mo} \\
6 \mathrm{Mo}\end{array}$ & $\begin{array}{l}7 \\
5\end{array}$ & $\begin{array}{l}161 \pm 51 \\
112 \pm 33\end{array}$ & $\begin{array}{l}0.286 \\
0.802\end{array}$ & $\begin{array}{l}565 \pm 154 \\
492 \pm 134\end{array}$ & $\begin{array}{l}0.528 \\
0.708\end{array}$ & $\begin{array}{l}583 \pm 1149 \\
556 \pm 663\end{array}$ & $\begin{array}{l}0.678 \\
0.589\end{array}$ & $\begin{array}{l}5576 \pm 5199 \\
2509 \pm 2337\end{array}$ & $\begin{array}{l}0.225 \\
0.987\end{array}$ \\
\hline High & $\begin{array}{l}3 \mathrm{Mo} \\
6 \mathrm{Mo}\end{array}$ & $\begin{array}{l}4 \\
6\end{array}$ & $\begin{array}{l}158 \pm 41 \\
203 \pm 119\end{array}$ & $\begin{array}{l}0.26 \\
0.199\end{array}$ & $\begin{array}{l}732 \pm 161 \\
897 \pm 150\end{array}$ & $\begin{array}{l}0.032 \\
0.017\end{array}$ & $\begin{array}{r}411 \pm 308 \\
1268 \pm 887\end{array}$ & $\begin{array}{l}0.878 \\
0.079\end{array}$ & $\begin{array}{l}9206 \pm 10174 \\
8445 \pm 10535\end{array}$ & $\begin{array}{l}0.155 \\
0.212\end{array}$ \\
\hline
\end{tabular}

Low, low copy number transgenic mice; High, high copy number transgenic mice; Fbn-1, mutated fibrillin-1 gene; pd Fbn-1, plasmid bearing Fbn-1; Anti-Topo Ab; cpm, counts per minute. Values are means \pm standard error of the mean (SEM) P values compared experimental groups to $\mathrm{C} 57 \mathrm{BL} / 6$. 

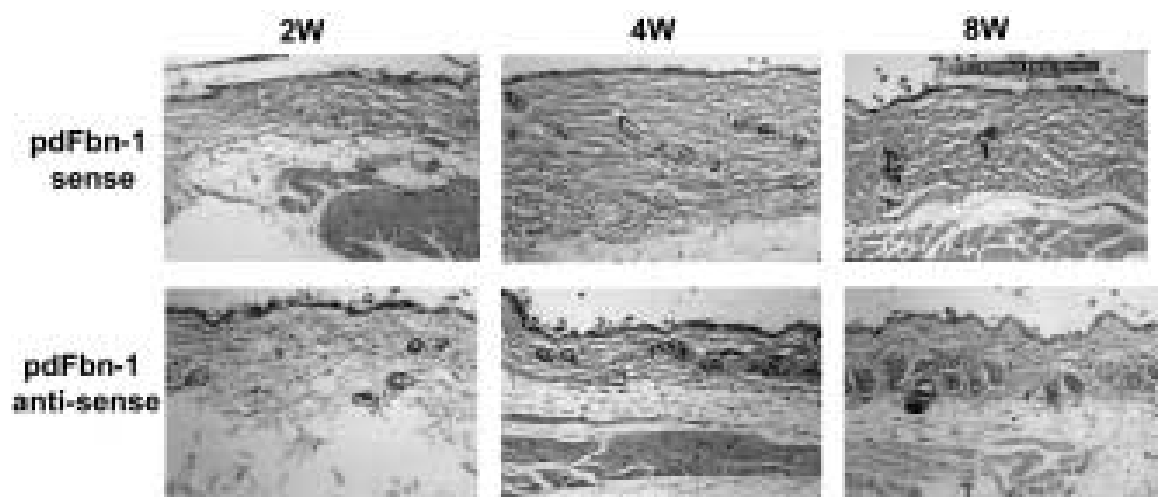

Fig. 7. Skin histopathology of mice injected after birth with plasmid bearing fibrillin-1 gene (pdFbn-1) containing the sense or anti-sense pdFbn-1 gene. The figures illustrate skin histology collected from mice 2, 4 and 8 weeks after the last injection with plasmid (30X).

jection exhibited a mild hyperplasia, but the skin thickness was not significantly increased, compared with normal mice (Table 2). The skin collected 12 weeks after injection of plasmid exhibited a normal structure (data not shown). This may be related to faster disappearance of plasmid from the skin in animals injected in the perinatal period (20) or dilution of plasmid from the site of injection by migration of Langerhans cells. We previously showed that the Langerhans cells, but not B cells, were transfected subsequent to s.c. or i.m. injection of plasmid, and they migrated to the lymph nodes where the peptides derived from the protein encoded by a foreign gene were expressed in plasmid stimulated T cells (21). The lung of these animals had normal alveoli ducts and alveoli diameter, except a strong inflammatory reaction was noted in mice scarified 4 weeks after the last injection of plasmid (Fig. 8). The data in Table 2 show that the skin thickness was slightly increased 2 weeks after injection $(p=0.6)$, but significantly increased in animals injected with plasmid bearing the sense gene 4 and 8 weeks after the last injection with vector $(p=0.0053$ and $p=0.04$, respectively, compared with normal mice). In contrast to TSK mice exhibiting an increase of dermal hydroxy-proline content, no significant increase of hydroxyproline was observed in skin biopsies collected 2 to 8 weeks after the last plasmid injection $(p<0.001)$. The data

Table 2. Characterization of tight skin syndrome in C57BL/6 mice immunized with plasmid expressing pdFbn-1 gene

\begin{tabular}{|c|c|c|c|c|c|c|c|c|}
\hline \multirow{2}{*}{$\begin{array}{l}\text { Mouse Strain } \\
\text { C57BL/6 }\end{array}$} & \multirow{2}{*}{$\begin{array}{c}\text { Age } \\
12 \mathrm{~W}\end{array}$} & \multirow{2}{*}{$\frac{N}{6}$} & \multicolumn{2}{|c|}{$\begin{array}{c}\text { Skin Thickness } \\
(\mu \mathrm{m})\end{array}$} & \multicolumn{2}{|c|}{$\begin{array}{l}\text { Hydroxyproline Content } \\
(\mu \mathrm{mol} / \mu \mathrm{g} \text { dry skin })\end{array}$} & \multicolumn{2}{|c|}{$\begin{array}{l}\text { Anti-Fbn-1 Ab } \\
(\text { (cpm) }\end{array}$} \\
\hline & & & $132 \pm 42$ & $\mathrm{P}$ & $518 \pm 88$ & $\mathrm{P}$ & $2529 \pm 2743$ & $\mathrm{P}$ \\
\hline TSK/+ & $12 \mathrm{~W}$ & 10 & $239 \pm 89$ & 0.0196 & $955 \pm 361$ & 0.013 & $11150 \pm 5707$ & 0.004 \\
\hline \multirow[t]{4}{*}{ Sense } & $2 \mathrm{~W}$ & 12 & $144 \pm 48$ & 0.625 & $620 \pm 31$ & 0.58 & $29701 \pm 9381$ & 0.000018 \\
\hline & $4 W$ & 4 & $279 \pm 82$ & 0.0053 & $553 \pm 45$ & 0.540 & $13475 \pm 11464$ & 0.05 \\
\hline & $8 W$ & 3 & $230 \pm 85$ & 0.047 & $550 \pm 30$ & 0.640 & $9270 \pm 2843$ & 0.01 \\
\hline & $12 \mathrm{~W}$ & 9 & $157 \pm 57$ & 0.3741 & $630 \pm 89$ & 0.115 & $25246 \pm 11319$ & 0.00037 \\
\hline \multirow[t]{4}{*}{ Anti-sense } & $2 \mathrm{~W}$ & 5 & $148 \pm 29$ & 0.54 & $558 \pm 35$ & 0.442 & $2693 \pm 2357$ & 0.9 \\
\hline & $4 \mathrm{~W}$ & 5 & $166 \pm 50$ & 0.245 & $503 \pm 67$ & 0.775 & $7434 \pm 5689$ & 0.0928 \\
\hline & $6 \mathrm{~W}$ & 4 & $123 \pm 14$ & 0.786 & $570 \pm 42$ & 0.405 & $2443 \pm 1015$ & 0.98 \\
\hline & $8 W$ & 3 & $151 \pm 14$ & 0.491 & $723 \pm 23$ & 0.006 & $2745 \pm 1150$ & 0.9 \\
\hline
\end{tabular}

Values are means \pm standard error of the mean (SEM). P values compared experimental groups of C57BL/6. Fbn-1, mutated fibrillin-1 gene; pdFbn-1, plasmid bearing Fbn-1; TSK, tight skin mice Anti-Fbn-1 Ab,. 

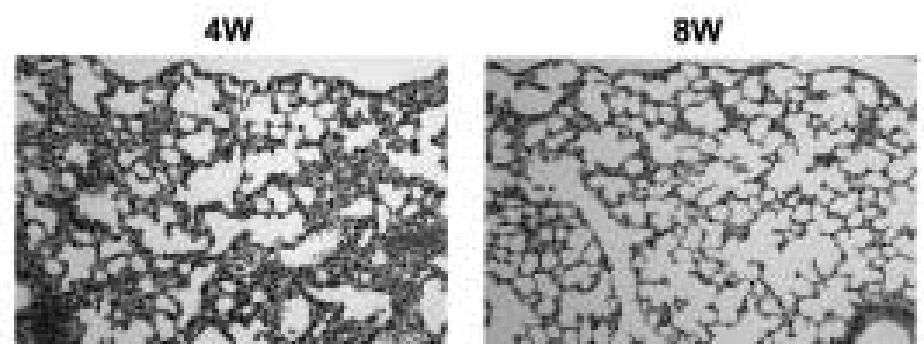

Fig. 8. Lung histopathology of mice injected after birth with plasmid bearing fibrillin-1 gene (pdFbn-1). Lung was collected 4 and 8 weeks after the last injection with plasmid (30X).

presented in Table 2 indicates that cutaneous, localized hyperplasia was transient, since the skin collected 12 weeks after the last injection with plasmid exhibited normal size $(p=$ 0.3741 ), compared with normal mice.

Anti-Fbn-1 autoantibodies were significantly increased in all groups of mice injected with plasmid containing the sense gene, but not in those injected with the non-sense gene. In all groups of mice, we did not detect antitopoisomerase I (data not shown).

\section{Discussion}

The TSK syndrome comprises skin thickening, lung emphysema, connective tissue hyperplasia of cartilage, (1) and presence of antibodies specific for human scleroderma target antigens (5). It was thought that the TSK syndrome resulted from a dominant autosomal mutation located on chromosome 2 (1). Later, it was shown that in TSK mice the Fbn-1 gene was mutated (i.e., duplication of exons 17-40) (10). It is transcribed (12) and translated in both TSK/- and TSK/TSK fibroblasts, as well as in
Cos7 cells transfected stable with the pdFbn-1 gene (22). The pdFbn-1 gene also is located on band $\mathrm{F}$ of chromosome 2 and is mapped 0 $0.7 \mathrm{cM}$ from the TSK mutation that explains cosegregation of TSK syndrome with the pdFbn-1 gene in Fl mice (12). The concept that the TSK mutation is the pdFbn-l gene was challenged by an observation reporting two recombinants between the TSK mutation and the Fbn-1 locus in backcross progeny obtained from crossing (TSK/- $x$ Mus spretus) Fl $X$ C57BL/6 pa/pa mice (13).

To test the hypothesis that the pdFbn-1 gene is indeed identical with the TSK mutation, we took two approaches: (i) preparation of pdFbn-1 Tg mice; and (ii) injection of $\mathrm{C} 57 \mathrm{Bl} / 6$ newborn mice with a plasmid expressing the pdFbn-1 gene under the control of CMV promoter. The results summarized in Table 3 show that high copy number Tg mice develop cutaneous hyperplasia paralleled by an increased content of dermal hydroxyproline and anti-topoisomerase autoantibodies, but not lung emphysema. Cutaneous hyperplasia appears permanent, since it is observed in 3- and 6-month-old $\mathrm{Tg}$ mice. The data presented in

Table 3. Summary of studies of tight skin mice (TSK) phenotype

\begin{tabular}{lccccc}
\hline Mice & $\begin{array}{c}\text { Skin } \\
\text { Thickness }\end{array}$ & $\begin{array}{c}\text { Hydroxyproline } \\
\text { Content }\end{array}$ & $\begin{array}{c}\text { Lung } \\
\text { Emphysema }\end{array}$ & Topol & Autoantibodies \\
\hline C57BL/6 & N & N & - & - & - \\
TSK/+ & I & I & + & - & + \\
pdFbn-1 Tg & I & I & - & - & + \\
C57Bl/6 & T & I & & + \\
+ plasmid & & & & + \\
\hline
\end{tabular}

N, normal; I, increased; T, transient; +, present; -, absent; Fbn-1, mutated fibrillin-1 gene; pdFbn-1 Tg, transgenic mice with plasmid bearing Fbn-1; topol, topoisomerase $T$. 
Table 1 and 3 strongly suggest that both incidence of TSK syndrome and skin thickening depend on the number of copy of transgenes. In contrast, the mice injected with plasmid exhibit an increase of dermal content of hydroxyproline 2 weeks after the last injection of plasmid and a transient cutaneous hyperplasia after 4 to 8 weeks, which vanished by 12 weeks. The cutaneous hyperplasia localizes at the site of injection of plasmid. These mice, like $\mathrm{Tg}$ mice, do not exhibit lung emphysema, but show cellular infiltration of interalveolar septa in the case of mice examined 4 weeks after the injection of plasmid. All mice injected with plasmid expressing the sense gene produced anti-Fbn- 1 autoantibodies.

From these results several conclusions can be drawn. First, the pdFbn-1 gene contributes to the occurrence of cutaneous hyperplasia. Continuous high expression of the mutated gene in high copy number $\mathrm{Tg}$ mice causes a long-lasting hyperplasia, like that found in human scleroderma. In contrast to human localized, linear scleroderma and morphea exhibiting permanent hyperplasia, localized cutaneous hyperplasia observed in mice injected with plasmid containing the sense pdFbn-l gene is transient. This may be due to a decrease in the number fibroblasts or Langerhans cells transfected subsequent to dilution of plasmid, leading to decreased local production of mutated protein. This explanation is in agreement with the low frequency of low copy number of $\mathrm{Tg}$ mice developing cutaneous hyperplasia. Taken together, these observations suggest that mutated protein should reach a certain threshold in order to contribute to skin thickness.

Second, that there is dissociation between cutaneous hyperplasia and lung emphysema. Lack of lung emphysema in pdFbn-1 Tg mice may be due to: (i) differences in temporal and spatial expression of endogenous Fbn-l gene in $\mathrm{Tg}$ and TSK/+ mice; or (ii) that an additional gene controls lung emphysema in TSK/+ mice. The putative gene controlling lung emphysema should be closely located $(<1 \mathrm{cM})$ in order to cosegregate in Fl mice without the occurrence of recombinants during several generations. Actually, we did not find lung alterations in $50 \%$ of $+/+\mathrm{pa} /+$ mice obtained from breeding of $\mathrm{TSK} /+\mathrm{x} \mathrm{C57Bl} / 6 \mathrm{pa} / \mathrm{pa}$, nor in $+/+\mathrm{pa} / \mathrm{pa}$ mice obtained from crossing (TSK/ + x C57Bl/6 pa/pa) F1 with C57BL/6 pa/pa mice. This suggests that the TSK mutation and a putative gene controlling emphysema should be closely linked, since two different genes located in a segment of DNA $>1 \mathrm{cM}$ segregate independently and the frequency of recombinants is $1 \%$ per generation. It is noteworthy that in another study we found that TSK/+ Il-4R-/-, which do not develop cutaneous hyperplasia, exhibited lung emphysema (McGaha et al. unpublished results). Taken together, these observations show that, although skin thickness is due to a single gene defect as it was thought by Green et al. (1), the TSK syndrome might be multifactorial.

Third, anti-topoisomerase autoantibodies pathognomonic for human systemic sclerosis (23), present in TSK mice (24) and in Tg mice, were not found in mice injected with plasmid. This suggests that the occurrence of these antibodies require long-lasting alteration of extracellular matrix protein, which, by an unknown mechanism, may favor the release of nuclear antigens.

Fourth, that mutated Fbn-1 protein is immunogenic, since the mice injected with plasmid produced anti-Fbn-1 autoantibodies like TSK/+ mice. Previously, we reported that the amount of wild-type Fbn-1 protein produced by TSK/+ fibroblasts was higher than the amount of mutated protein (22). This observation suggests that the mutated Fbn-1 protein is less stable and, therefore, can be more easily processed to generate peptides able to stimulate Th2 cells that cooperate with B cells to produce anti-Fbn-1 autoantibodies. Our data are in agreement with those reported by Costagliola et al. (25), showing that the injection with a plasmid expressing thyroid stimulating hormone receptor (TSHR) gene induced in mice anti-TSHR antibodies and Graves'-like syndrome. High frequency of anti-Fbn-1 antibodies present in TSK mice (16) were also found in American Indian Choctaw Oklahoma tribe patients afflicted by scleroderma (26). This tribe has the highest prevalence of systemic sclerosis (SSc) (27) and has multiple microsatellite alleles near the Fbn-1 locus, allowing the definition of $2 \mathrm{cM}$ haplotype associated with SSc (28). In addition, high frequency of anti-Fbn-1 autoantibodies was found in Japanese and Caucasian patients with SSc localized scleroderma and celcinosis, Raynaud's esophageal dysmobility, sclerodectyly and teleangiectasia (CREST) syndrome $(27,29)$. It is noteworthy that antiFbn- 1 autoantibodies were detected in the sera collected 12 weeks after the last injection of plasmid, when these mice exhibited normal structure of skin. This suggests generation of memory cells subsequent to immunization with 
DNA. This observation is in agreement with the data reported by Fiocco et al. (30), showing that circulating $\mathrm{T}$ helper cells in scleroderma exhibit a memory phenotype.

One may ask: what is the link between the occurrence of cutaneous hyperplasia and TSK mutation? Several scenarios may be envisioned, in light of the fact that TSK/+ JhD-/-mice develop cutaneous hyperplasia (12), indicating that autoantibodies are an epiphenomenon. First, it may be that mutated protein is less stable (22) and more easily degraded, and after processing, generates immunogenic or cryptic epitopes able to stimulate $T$ cells producing fibrogenic cytokines. It is well known that interleukin-4 (IL-4) and transforming growth factor- $\beta$ (TGF $\beta)$ up-regulate the expression of collagen genes (31-33).

Second, the mutated Fbn-1 protein has an increased number of TGF $\beta$ protein repeats, allowing the binding of more latent TGF $\beta$ than wild protein (21). The processed latent form may be released slowly, as in the active form, which causes a sustained stimulation of fibroblasts (10). Third, Kielty et al. (34) showed that mutated protein polymerizes and become incorporated into beaded microfibrils with altered molecular organization, leading to an altered general structure of extra cellular matrix (ECM), which may favor the deposition of collagen.

In conclusion the results of this study show that: (1) the expression of pdFbn-1 gene in $\mathrm{Tg}$ mice, as in TSK mice, is associated with increased collagen synthesis and skin fibrosis; (2) in contrast to TSK mice, the Tg mice do not develop lung emphysema; and (3) as we demonstrated for the first time, a localized and transient skin sclerosis can be induced subsequent to injection of plasmid in newborn mice.

\section{Acknowledgment}

This study was supported by grants from the Scleroderma Foundation and NIH-NIAID POI AI 2467-11 and by the C.O.E.grant from the Ministry of Education, Science, Sport and Culture of Japan.

\section{References}

1. Green MC, Sweet HO, Bunker LE. (1976) Tightskin a new mutation of the mouse causing excessive growth of connective tissue and skeleton. Amer. J. Pathol. 82: 493-507.
2. Jablonska S, Schubert H, Kikuchi I. (1989) Congenital fascial dystrophy: stiff skin syndrome-a human counterpart of the tight-skin mouse. $J$. Amer. Acad. Dermatol. 21: 943-950.

3. Rossi GA, Hunninghake GW, Gadek JE, et al. (1984) Hereditary emphysema in the tight skin mice. Amer. Rev. Resp. Dis. 123: 680-695.

4. Osborn TG, Bashey RI, Moore TL, Fisher VW. (1987) Collagenous abnormalities in the heart of tight-skin mice. J. Mol. Cell. Cardiol. 19: 581-587.

5. Bona C, Rothfield N. (1994) Autoantibodies in scleroderma and tight skin mice. Curr. Opin. Immunol. 6: 931-937.

6. Osborn TG, Bauer NE, Ross SC, Moore TL, Zuckner J. (1983) The tight-skin mouse:physical and biochemical properties of the skin. $J$. Rheumatol. 10: 793-796.

7. Jimenez SA, Williams CJ, Myers C, Bashey RI. (1986) Increased collagen biosynthesis and increased expression of type I and type III procollagen genes in tight skin mose fibroblasts. J. Biol. Chem. 261: 657-662.

8. Ross RC, Osborn TG, Dorner RW, Zuckner J. (1983) Glycoamino glycan content in the skin of tight skin mice. Arth. Rheum. 26: 653-657.

9. Li X, Pereira L, Zhang H, et al. (1993) Fibrillin genes map to regions of conserved mouse/human synteny mouse chromosome 2 and 18 . Genome 18: 667-672.

10. Siracusa LD, McGrath R, Ma Q, et al. (1996) A tandem duplication within fibrillin 1 gene is associated with the tight skin mutation. Genome Res. 6: 300-313.

11. Bona CA, Murai C, Casares S, Nishimura H, Honjo T, Matsuda F. (1997) Structure of the mutated Fibrillin-1 gene in the tight skin mice. DNA Res. 4: 267-271.

12. Kasturi KN, Hatakeyama, A, Murai C, Gordon R, Phelps RG, Bona CA. (1997) B-cell deficiency does not abrogate development of cutaneous hyperplasia in mice inheriting the defective Fibrillin1 gene. J. Autoimmunity 10: 505-517.

13. Doute R, Clark SH. (1994) Tight-skin maps on chromosome 2 within the region of linkage homology with human chromosome 15. Genomics 22: 223-225.

14. Phelps R, Daian C, Shibata S, Fleischmajer R, Bona C. (1993) Induction of skin fibrosis and autoantibodies by infusion of immunocompetent cells from tight skin into pa/pa mice. $J$. $A u$ toimmun. 6: 701-718.

15. Hatakeyama A, Kasturi KN, Wolf I, Phelps R, Bona C. (1996) Correlation between the concentration of serum anti-topoisomerase I autoantibodies and histological and biochemical alterations in TSK mice. Cell. Immunol. 167: 135140.

16. Murai C, Kasturi KN, Bona C. (1998) Spontaneous occurrence of anti-Fibrillin-1 autoantibodies in tight skin mice. Autoimmunity 28: 151-155. 
17. Bona C. (1999) Genetic defects in tight skin mice developing a scleroderma-like syndrome. Curr. Dir. Autoimmun. 1: 194-207.

18. Wolff JA, Maloe RW, Williams P, et al. (1990) Direct gene transfer into mose muscle in vivo. Science 247: 1465-1468.

19. Tige RA, Corr M, Roman M, Ratz E. (1998) Gene vaccination: plasmid DNA is more just than a blueprint. Immunol. Today 19: 89-97.

20. Bot A, Bot S, Garcia-Sastre A, Bona C. (1998) Protective cellular immunity against influenza virus induced by plasmid inoculation of newborn mice. Dev. Immunol. 5: 197-2 10.

21. Casares S, Inaba K, Brumeanu T-D, Steiman RM, Bona C. (1997) Antigen presentation by dendritic cells after immunization with DNA encoding a MHC class II-peptide viral epitope. J. Exp. Med. 186: 1481-1486.

22. Saito I, Nishimura H, Brumeanu T-D, et al. (1999) Characterization of mutated protein encoded by partially duplicated fibrillin-1 gene in tight skin mice. Mol. Immunol. 36: 169-176.

23. Shero JH, Bordwell B, Rothfield NF, Earnshaw WC. (1986) High titers of autoantibodies to topoisomeraseI (Scl-70) in sera from scleroderma patients. Science 231: 727-740.

24. Muryoi T, Kasturi KN, Kafina MJ, et al. (1992) Anti-topoisomerase I monoclonal autoantibodies from scleroderma patients and tight skin mouse interact with similar epitopes. J. Exp. Med. 175: 1103-1109.

25. Costagliola S, Rodien P, Many M-C, Ludgate M, Vassart G. (1998) Genetic immunization against the human throtropin receptor causes and allows production of monoclonal antibodies recognizing the native receptor. J. Immunol. 160: 1485-1465.
26. Tan FK, Arnett FC, Antohi S, et al. (1999) Autoantibodies to the extracellular matrix microfibrillar protein, Fibrillin-1, in patients with scleroderma and other connective tissue diseases. J. Immunol. 163: 1066-1072.

27. Arnett FC, Howard F, Tan F, et al. (1996) Increased prevalence of systemic sclerosis in a native American tribe in Oklahoma. Arth. Rheum. 39: 1362-1370.

28. Arnett FC, Tan FK, Uziel Y, et al. (1999) Autoantibodies to extracellular matrix microfibrillar protein, Fibrillin-1, in patients with localized scleroderma. Arth. Rheum. 42: 2656- 2659.

29. Tan FK, Stivers DN, Foster MW, et al. (1998) Microsatellite markers near fibrillin-l gene on human chromosome $15 \mathrm{q}$ are associated with scleroderma in a Native American population. Arth. Rheum. 41: 1729-1737.

30. Fiocco U, Rosada M, Cozzi L, et al. (1993) Early phenotypic activation of circulating helper memory $\mathrm{T}$ cells in scleroderma. Ann. Rheum. Dis. 52: 272-277.

31. Unemori EN, Amato EP. (1991) Connective tissue metabolism including cytokines in scleroderma. Curr. Opin. Rheum. 3: 953-956.

32. Nedelman BW, Wigley FM, Stair RW. (1992) Interleukin-1, interleukin-4, interleukin-6, tumor necrosis $\alpha$ and interferon- $\gamma$ levels in sera from patients with scleroderma. Arth. Rheum. 35: 67- 72.

33. Kovacs EJ, DiPietro LA. (1994) Fibrogenic cytokines and connective tissue production. FASEB J. 8: 854-861.

34. Kielty JM, Ragunath M, Siracusa LD, et al. (1998) The tight skin mouse: demonstration of mutant Fibrillin-1 production and assembly into abnormal microfibrils. J. Cell Biol. 140: 1156-1166. 